\title{
North-south differences in circadian eclosion rhythm in European populations of Drosophila subobscura
}

\author{
P. LANKINEN \\ Department of Genetics, University of Oulu, Linnanmaa, SF-90570 Oulu, Finland
}

\begin{abstract}
The circadian pupal eclosion rhythm was studied in 12 strains of Drosophila subobscura originating from two regions: Scandinavia $\left(56-63^{\circ} \mathrm{N}\right)$, and the Canary Islands $\left(28^{\circ} \mathrm{N}\right)$. In most parameters of the rhythm, ample variability was found both within and between the regions. Among the strains the phase of the eclosion median in an entraining diel light-dark cycle varied by $8.1 \mathrm{~h}$, and the period of the free-running rhythm $(\tau)$ by $2.2 \mathrm{~h}$. In the comparison between the two regions, the Scandinavian entrained rhythm had on average a $2.8 \mathrm{~h}$ earlier phase, $\tau$ was $0.9 \mathrm{~h}$ shorter, and the amplitude of the rhythm was lower. Of the rhythm parameters, early phase was correlated with short $\tau(r=0.76)$, and the amplitude of the entrained rhythm was correlated with the amplitude of the free-running rhythm $(r=0.98)$. In addition to the geographical variation, a putative arhythmic recessive autosomal mutant was found to segregate in one Scandinavian strain. The lack of photoperiodic adult diapause was confirmed in $D$. subobscura. The results show that the circadian eclosion rhythm in a nonphotoperiodic species can vary latitudinally in a fashion similar to that of photoperiodic species.
\end{abstract}

Keywords: circadian rhythm, developmental time, Drosophila subobscura, latitudinal cline, photoperiodic diapause, rhythm mutant.

\section{Introduction}

Drosophila subobscura has been the traditional subject of study of European ecological population geneticists (reviewed by Krimbas \& Loukas, 1980). This is exemplified through papers published in diverse languages in even more diverse journals (e.g. Prevosti, 1968; Saura et al., 1973). D. subobscura has, accordingly, become Europe's answer to D. pseudoobscura in the New World. Interestingly, $D$. subobscura has recently (1978) invaded the Americas and is well established now in South and North America - in fact it may be well on the way to supplanting D. pseudoobscura and its relatives (Prevosti et al., 1988).

The main subject of research in D. subobscura has been the study of genetic polymorphism of such markers as chromosomal inversions and enzyme genes (recently reviewed by Krimbas \& Powell, 1992), and lately also DNA markers (Afonso et al., 1990; Latorre et al., 1992). The species has also been studied intensively from an ecological point of view (Krimbas \& Loukas, 1980).

The formal modelling of circadian rhythmicity in Drosophila, and in organisms in general, is based mainly on D. pseudoobscura (Pittendrigh, 1966, 1981; Winfree, 1980), a close relative of $D$. subobscura. The rhythm studies of $D$. pseudoobscura do not include any investigations of geographical variability; it has been rather neglected by using only a few well characterized strains. In the present paper, geographical variability in an important character, the circadian eclosion rhythm, was examined in D. subobscura.

\section{Materials and methods}

\section{Strains}

The strains originated from single females captured in Scandinavia or in the Canary Islands. The strains were: Kuopio 1, 3130 (strain number in Oulu), Finland, $62^{\circ} 55^{\prime} \mathrm{N}, 1990$ (the year of the capture); Kuopio 2, 3131, 1990; Hollola 1, 3107, Finland, $61^{\circ} 05^{\prime} \mathrm{N}$, 1984; Hollola 2, 3108, 1984; Kristiansand, 3103, Norway, 58 $05^{\prime} \mathrm{N}, 1981$; Öland, 3104, 56 $40^{\prime} \mathrm{N}$, Sweden, 1981; Karlskrona, 3105, 56 $10^{\prime} \mathrm{N}$, Sweden, 1981; Tenerife 1, 3125, $28^{\circ} 10^{\prime} \mathrm{N}$, Spain, 1983; Tenerife 2, 3122, 1983; Tenerife 3, 3120, 1983; 
Tenerife 4, 3124, 1983; Tenerife 5, 3123, 1983. The strains were kept as mass cultures on malt medium in continuous light at $19^{\circ} \mathrm{C}$ after their arrival in our laboratory.

\section{Recording the eclosion rhythm}

The methods for monitoring pupal eclosion rhythm and the definitions of the rhythm parameters have been described in detail earlier (Lankinen \& Lumme, 1982; Lankinen, 1986a,b). In short, the automatic registration apparatus is made of clear plastic. When a fly emerges in the eclosionometer, it pushes down the ball in front of it, and the falling ball is registered by a microswitch. Each emerged fly is thus seen in the recording paper, and the eclosions are counted hourly for further analysis.

For the entrained rhythm in light-dark (LD) cycles, the eclosionometers were in experimental chambers $\left(19 \pm 0.3^{\circ} \mathrm{C}\right.$, illumination by fluorescent tubes, 500-1000 lux). To monitor eclosion rhythms, the cultures were removed from the culture room (continuous light, $19^{\circ} \mathrm{C}$ ), the eclosionometers were loaded with pupae of mixed age, and transferred to the LDchambers during the light phase.

The free-running rhythm was studied in a separate climate-controlled room at $19 \pm 0.5^{\circ} \mathrm{C}$. Pupae were raised in the room at a continuous illumination of 500-1000 lux. The free-running rhythm was initiated by a single transfer from continuous light to continuous darkness by closing the loaded eclosionometers into the dark-boxes in the same climate room.

\section{Defining the eclosion rhythm parameters}

The entrained rhythm of eclosion. The daily pattern of eclosion was obtained from the steady-state rhythm of the fourth and later days in LD conditions by summing the hourly eclosions over several days. The figures give the rhythm as percentages/hour in order to make the shapes of daily distributions comparable between the strains. The median time of eclosion was calculated as hours from lights-off, and defined e.g. as $\psi_{\mathrm{LD} 3: 21}$ for the median phase of eclosion in LD 3:21. The amplitude of the rhythm ( s.d.ecl $_{\text {ec }}$ ) was calculated as the standard deviation around the mean of the hourly distribution of the diel rhythm. Accordingly, the smaller the s.d.ecl, the higher the amplitude.

The free-running rhythm of eclosion. The replicate recordings for each experimental group were summed hourly, and the rhythm is presented in the figures as percentages of eclosion over gliding intervals of $24 \mathrm{~h}$. After that, the sum of hourly eclosion percentages is the same (100 per cent) in any $24 \mathrm{~h}$ period over the whole registration. This eliminates possible differences in the age distribution and/or total number of the pupae, and allows comparison between eclosion peaks of successive days, or whole eclosion profiles of different strains. The period of the free-running rhythm $(\tau)$ was based on the slope of the linear regression line of the daily timing of the second and later medians of eclosion peaks. The phase of eclosion in the freerunning rhythm $\left(\psi_{\mathrm{EL}}\right)$ was the median of the 'first-day peak' after lights-off. The eclosion is typically rhythmic only from the second day on, when the rhythm is initiated as in the present study (Fig. 3). $\psi_{\mathrm{EL}}$ was estimated as the intercept of the linear regression line and the hour axis on day 1 (see Fig. 4). S.E., the standard error in $\tau$, is the standard error of the regression slope in the estimation of $\tau$. The amplitude of the rhythm (Amp) was calculated as the mean of the five highest hourly percentages in each daily eclosion peak over peaks 3-7. The possible range of Amp values is, accordingly, from 4.17 per cent (no rhythmicity at all) to 20 per cent (all five peaks within $5 \mathrm{~h}$ each).

\section{Results}

\section{The phase of eclosion in light-dark cycles}

The summary of the rhythm characteristics of the strains is given in Table 1 . The phase of eclosion was studied in all strains in a 'short-day' condition of LD $3: 21$, where the eclosions occurred mainly during the dark phase of the photoperiod. Figure 1 shows the eclosion rhythms in strains representing the observed range of $8.1 \mathrm{~h}$ in the median of eclosion time $\left(\psi_{\mathrm{LD} 3: 21}\right)$. In LD 3:21, eclosions within a strain were normally distributed, and the differences between strains were most pronounced. Four strains were additionally studied in several LD cycles (Fig. 2). The order of the eclosion medians of the strains remained principally the same as in LD $3: 21$, but the differences were smaller. When the rhythms were studied in longer photophases, the eclosions fell nearer to dawn. Then many flies are stimulated to react directly to the lightson signal, and the distribution of eclosions may be skewed. In a very long daylength LD $21: 3$, the entrainment was weak, and the phases in the Tenerife strains could not be determined unambiguously.

Results for entrained rhythm were based in each experimental group on the average of 254 emerged flies (altogether 5600), 7.5 days of recording, and 1.3 replicate registrations. 
Table 1 Characteristics of the rhythm in strains of D. subobscura. Phase $\left(\psi_{\mathrm{LD} 3: 21}\right.$, h) and amplitude s.d.ecl,$h)$ of the entrained eclosion rhythm in LD 3:21; Period $(\tau, \mathrm{h})$ standard error of the period (S.E., h), phase $\left(\psi_{\mathrm{EL}}, \mathrm{h}\right.$ ) and amplitude (Amp, \%) of the free-running rhythm

\begin{tabular}{|c|c|c|c|c|c|}
\hline \multirow[b]{2}{*}{ Strain } & \multicolumn{2}{|c|}{ Entrained rhythm } & \multicolumn{3}{|c|}{ Free-running rhythm } \\
\hline & $\psi_{\mathrm{LD} \mathrm{3:21}}$ & s.d. $_{\text {ecl }}$ & $\tau \pm$ S.E. & $\psi_{\mathrm{EL}}$ & Amp \\
\hline \multicolumn{6}{|l|}{ Scandinavia } \\
\hline Kuоpio 1 & 16.7 & 2.56 & $24.3 \pm 0.2$ & 13.3 & 11.0 \\
\hline Kиорiо 2 & 16.1 & 2.97 & $24.5 \pm 0.3$ & 12.1 & 10.8 \\
\hline Hollola 1 & 12.4 & 1.92 & $24.1 \pm 0.2$ & 10.7 & 12.5 \\
\hline Hollola 2 & 15.9 & 2.00 & $24.6 \pm 0.1$ & 12.3 & 12.3 \\
\hline Kristiansand & 14.6 & 3.56 & $24.8 \pm 0.2$ & 10.5 & 9.0 \\
\hline Öland & 15.8 & 1.74 & $25.9 \pm 0.1$ & 12.4 & 13.8 \\
\hline Karlskrona & 17.7 & 1.47 & $25.8 \pm 0.2$ & 12.1 & 14.0 \\
\hline \multicolumn{6}{|l|}{ Canary Islands } \\
\hline Tenerife 1 & 16.9 & 1.18 & $25.1 \pm 0.2$ & 12.3 & 14.9 \\
\hline Tenerife 2 & 18.2 & 1.09 & $25.5 \pm 0.1$ & 12.2 & 14.9 \\
\hline Tenerife 3 & 18.2 & 1.24 & $26.1 \pm 0.1$ & 9.3 & 14.7 \\
\hline Tenerife 4 & 18.0 & 1.57 & $26.1 \pm 0.2$ & 9.3 & 13.2 \\
\hline Tenerife 5 & 20.5 & 1.76 & $26.3 \pm 0.1$ & 12.1 & 13.2 \\
\hline
\end{tabular}

\section{Free-running rhythm of eclosion}

The free-running rhythm in $D$. subobscura was of a high amplitude, and the rhythm continued undamped throughout the 8-10 days of emergence of a pupal cohort (Fig. 3; 8 first days are shown). The period of the free-running rhythm $(\tau)$ ranged from $24.1 \mathrm{~h}$ in Hollola 1 to $26.3 \mathrm{~h}$ in Tenerife 5 (Table 1). The median times of daily eclosion peaks during the free-run of the rhythm in six representative strains are shown in Fig. 4. The hour axis in Fig. 4 is $24 \mathrm{~h}$, which means that when the medians of the rhythm move to the right during successive days, $\tau$ is longer than $24 \mathrm{~h} . \psi_{\mathrm{EL}}$, the estimated 'starting point' of the rhythm, ranged from $9.3 \mathrm{~h}$ to $13.3 \mathrm{~h}$. $\psi_{\mathrm{EL}}$ of Tenerife 5 is shown in Fig. 4 as an example of the method used to estimate it.

Results for the free-running rhythm of a strain were based on the average of 3.7 replicate recordings, and 1615 emerged flies (altogether 19,400).

\section{The aberrant eclosion rhythm in Kristiansand}

In the Kristiansand strain both the entrained and the free-running rhythm had a lower amplitude than in other strains (Table 1, Figs 1 and 2). The strain was captured in 1981, and the rhythms presented for the strain in this study were recorded in the autumn of 1983. When the strain was restudied in 1990 , it had become almost arhythmic. The arhythmicity in the strain is probably due to one recessive autosomal allele
(Lankinen, 1993b). In 1983 the arhythmic allele was segregating in the strain, and has later been fixed or almost fixed in the strain.

In spite of the partial arhythmicity, the parameters for the phase and period of the rhythm in Kristiansand were measurable comparatively with the other strains. The amplitude parameters (s.d.ecl and Amp) of Kristiansand were omitted, because of their aberrant nature, in the statistical analysis of north-south differences in the rhythm.

\section{North-south differences in the rhythm}

The strains represented northern $\left(56-63^{\circ} \mathrm{N}\right)$ and southern $\left(28^{\circ} \mathrm{N}\right)$ margins of European distribution of D. subobscura. In spite of considerable variability within Scandinavia or the Canary Islands (Table 1), the means of the regions differed significantly $(P<0.05$, $t$-test) in four of the five characteristics of the rhythm (Table 2). On average, in the north, the entrained rhythm $\left(\psi_{\mathrm{LD} 3: 21}\right)$ had a $2.8 \mathrm{~h}$ earlier phase, the period of the free-running rhythm $(\tau)$ was $0.9 \mathrm{~h}$ shorter, and the amplitudes of both rhythms were lower.

The local ranges in the values of the characteristics exceeded the difference of the means between Scandinavia and the Canary Islands. Within-region variability was for example $5.3 \mathrm{~h}$ in Scandinavia and $3.6 \mathrm{~h}$ in the Canary Islands in the entrained rhythm. If only a few strains had been studied, they might accidentally have 

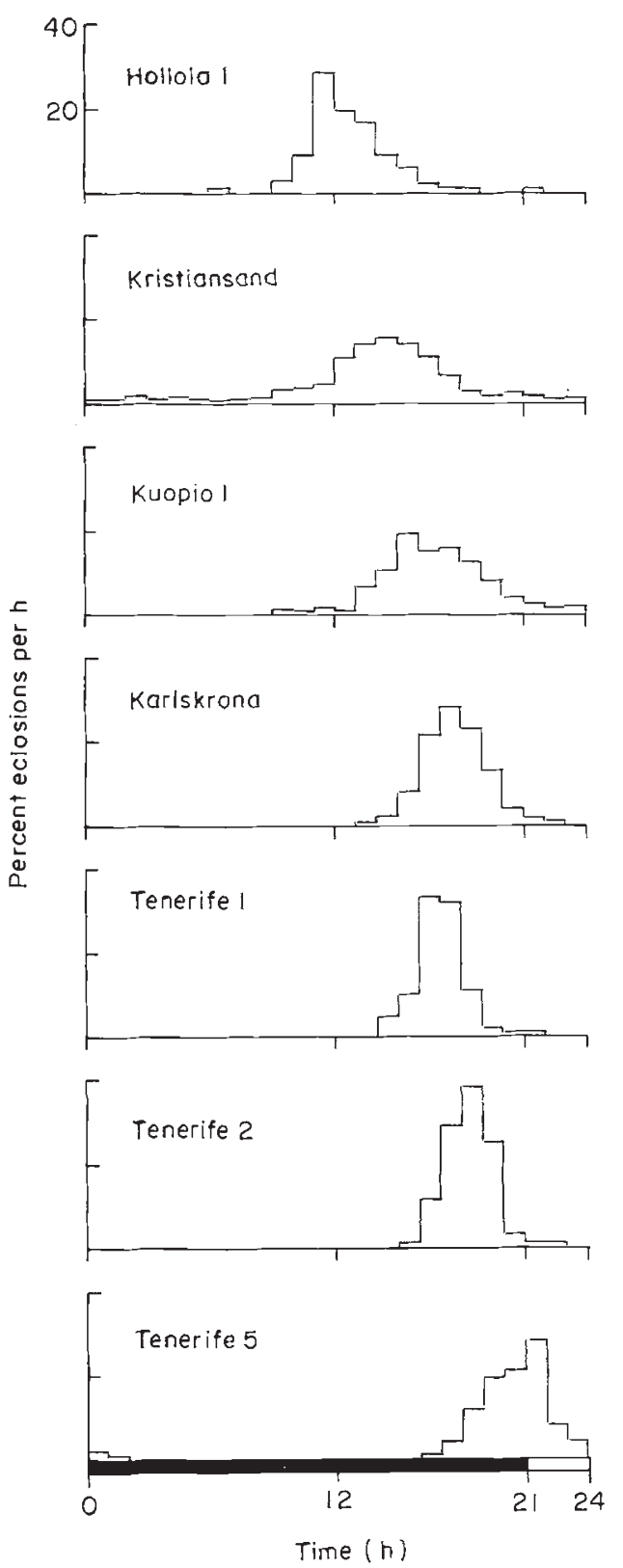

Fig. 1 The entrained pupal eclosion rhythm in light-dark cycle LD $3: 21\left(19^{\circ} \mathrm{C}\right)$ in strains of $D$. subobscura originating from Scandinavia and the Canary Islands. The strains with earliest and latest eclosion in both regions are included in the figure.

represented the opposite direction in north-south differences.

\section{Correlation between the rhythm characteristics}

The statistical correlations between the rhythm characteristics of the strains are shown in Table 3. Early phase in $\operatorname{LD~3:21}\left(\psi_{\mathrm{LD} 3: 21}\right)$ was found with short period of free-running rhythm (Fig. 5), and high amplitude of

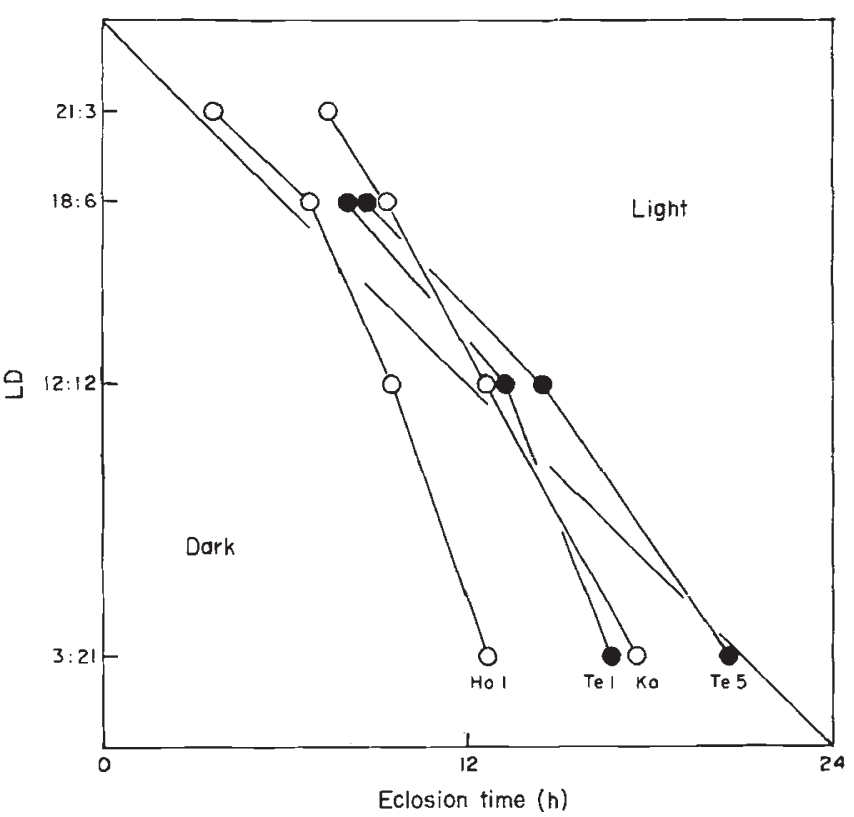

Fig. 2 The phase of eclosion medians as a function of photoperiod $\left(19^{\circ} \mathrm{C}\right)$ in two strains from Scandinavia (open circles) and two strains from the Canary Islands (filled circles). The strains are: Ho $1=$ Hollola $1, \mathrm{Ka}=$ Karlskrona, $\mathrm{Te} 1$

$=$ Tenerife 1 ; Te $5=$ Tenerife 5 .

entrained rhythm (small value of s.d.ecl ) was found with high amplitude of free-running rhythm (large value of Amp). The two parameters of the phase of the rhythm $\left(\psi_{\mathrm{LD} 3: 21}\right.$ and $\left.\psi_{\mathrm{EL}}\right)$ were independent of each other.

\section{The duration of the pupal stage}

The egg-to-adult development time of $D$. subobscura is known to be variable between geographical strains (Budnik et al., 1991). The duration of emergence in a mixed age pupal cohort is a rough measure of the time from pupation to eclosion (Ikeda \& Saito, 1983; Kyriacou et al., 1990). This was thus obtained as a byproduct of my experiments. The duration depended on the strain, and ranged from about $185 \mathrm{~h}$ (Hollola 1) to $240 \mathrm{~h}$ (Karlskrona) in the free-running rhythms. The difference between Scandinavia (mean $=210 \mathrm{~h}$ ) and the Canary Islands (mean $=218 \mathrm{~h}$ ) was not significant. Interestingly, the duration was correlated with $\tau$ $(r=0.78, P<0.001)$ : the longer the period in the rhythm, the longer the developmental time.

\section{The lack of photoperiodic diapause in D. subobscura}

Although actively searched for, photoperiodism has not been found in D. subobscura either in laboratory experiments or when observed in outdoor populations in England (Begon, 1976), and in Switzerland (Walter, 


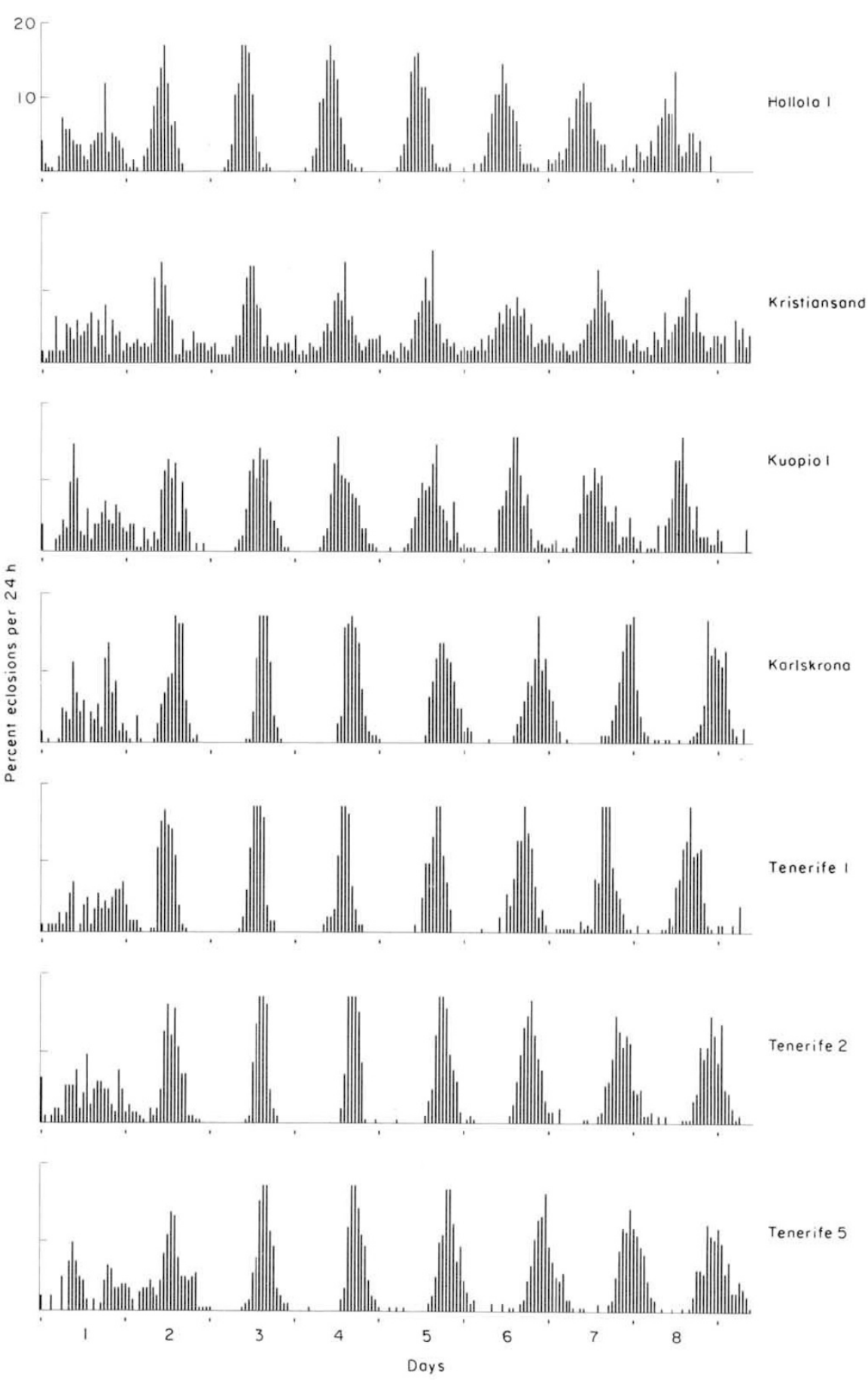

Fig. 3 The free-running rhythms of eclosion in strains of $D$. subobscura originating from Scandinavia and the Canary Islands. The rhythms were initiated by a transfer from continuous light to continuous darkness $\left(19^{\circ} \mathrm{C}\right)$. The distribution of eclosion is presented as percentages (cropped at 17 per cent) over gliding intervals of $24 \mathrm{~h}$.
1990). Saunders et al. (1989) found unexpectedly, by using low temperature, a photoperiodic adult ovarian diapause in $D$. melanogaster, which earlier had been regarded as a non-photoperiodic species. Inspired by the discovery of Saunders, we tried to induce diapause in $D$. subobscura by applying what was thought to be a very strong diapause inducing condition of LD 12:12 at a low temperature of $11^{\circ} \mathrm{C}$, and by raising the cultures in those conditions, from the larval stage. In the strains Hollola 1, Kristiansand and Tenerife 5, no indication of diapause was found in any of the experimental groups; the females $(n=104)$ when dissected at the age of 2-4 weeks always had fully developed ovaries. As a control our wild $D$. melanogaster strain from Paris was studied simultaneously. The Paris strain had diapausing females with undeveloped ovaries containing no mature eggs ( 25 per cent, $n=102$ ), or poorly developed ovaries, as expected on the results of 
Saunders. Thus, even the northern populations of $D$. subobscura lack diapause.

\section{Discussion}

The search for genetic variation in circadian rhythms of Drosophila has been based on two different approaches: screening between-strain variation, or by

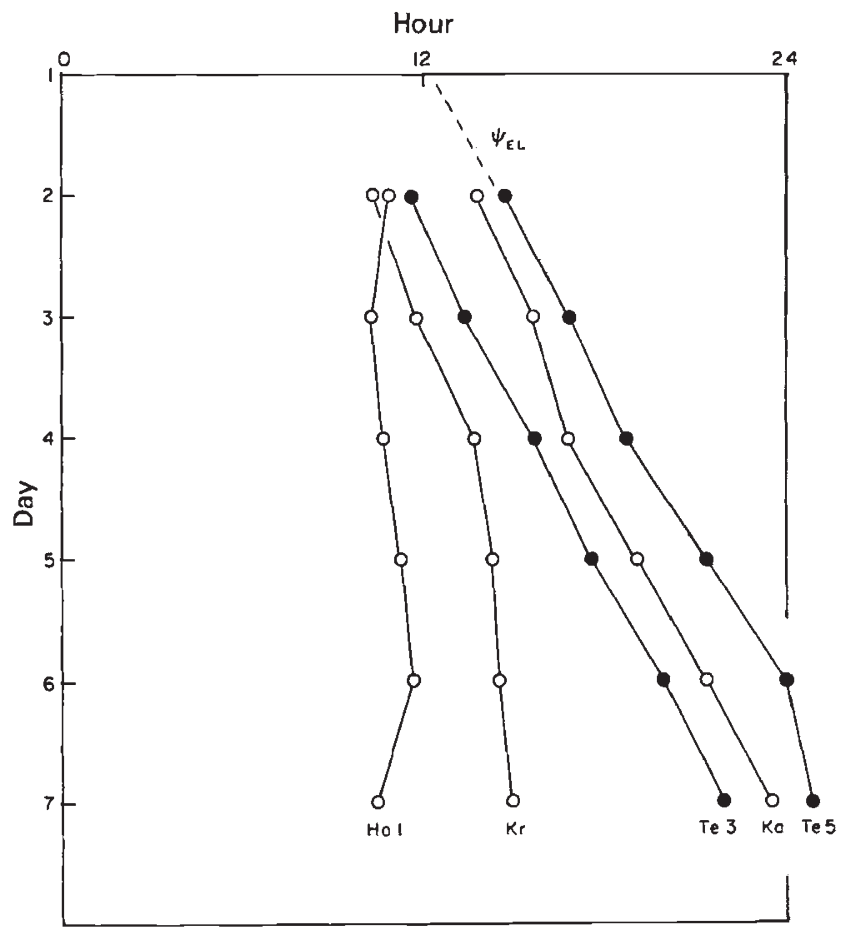

Fig. 4 The free-running rhythm in three strains from Scandinavia (open circles) and two strains from the Canary Islands (filled circles). The rhythms are presented as the median timing of successive eclosion peaks. The estimated median of day $1\left(\psi_{\mathrm{EL}}=12.1 \mathrm{~h}\right)$ is shown for the strain Te 5 . The strains are: Ho $1=$ Hollola $1, \mathrm{Kr}=$ Kristiansand, $\mathrm{Ka}=$ Karlskrona, $\mathrm{Te} 3=$ Tenerife $3, \mathrm{Te} 5=$ Tenerife 5 . inducing mutations. The most successful results with the latter approach are the X-linked per mutants of $D$. melanogaster (Konopka \& Benzer, 1971).

The screening of natural populations and induced mutants complement each other. Variability in natural populations may include different phenotypes, or may be based on different loci from induced mutants. Natural selection may act in a fashion different from the production of genetic variation in the laboratory. In addition, the range of variability occurring in the wild, and its potential adaptive value, is interesting.

\section{The amount of eclosion rhythm variation, and its geographical distribution}

There was ample variation of the circadian rhythmicity in the 12 strains of $D$. subobscura. The most extreme pair of strains, Hollola 1 and Tenerife 5, differed in their phase of eclosion in LD 3:21 ( $\left.\psi_{\mathrm{LD} 3: 21}\right)$ by $8.1 \mathrm{~h}$, and in the period of free-running rhythm by $2.2 \mathrm{~h}$. Virtually all variability between these two strains is autosomal (in preparation), in contrast to most chemically induced mutants ( $c f$. Hall, 1990). The actual range in nature is probably even wider than shown here, considering the relatively low number of strains, and the ample within-region variability.

Table 3 Correlations between the rhythm characteristics among the strains of $D$. subobscura. The characteristics are explained in Table 1

\begin{tabular}{llrrr}
\hline Characteristic & s.d. $_{\text {ecl }}$ & \multicolumn{1}{l}{$\tau$} & \multicolumn{1}{c}{$\psi_{\mathrm{EL}}$} & \multicolumn{1}{c}{ Amp } \\
\hline$\psi_{\mathrm{LD} \mathrm{3:21}}$ & -0.47 & $0.76^{* *}$ & 0.06 & 0.48 \\
s.d. $_{\text {ecl }}$ & & $-0.56^{\circ}$ & 0.06 & $-0.98^{* * *}$ \\
$\tau$ & & & -0.31 & $0.60^{*}$ \\
$\psi_{\mathrm{EL}}$ & & & & -0.03 \\
\hline
\end{tabular}

${ }^{* * *} P<0.001 ;{ }^{* *} P<0.01 ; * P<0.05 ;{ }^{\circ} P<0.10$.

Table 2 Comparison of the characteristics of the rhythm between Scandinavia and the Canary Islands. Means, standard deviations of the means, and the number of strains $(n)$ are given. $P$ is the probability for the difference between the regions (t-test). The characteristics are explained in Table 1

\begin{tabular}{|c|c|c|c|c|c|}
\hline \multirow[b]{2}{*}{ Region } & \multicolumn{2}{|c|}{ Entrained rhythm } & \multicolumn{3}{|c|}{ Free-running rhythm } \\
\hline & $\psi_{\mathrm{LD} 3: 21}$ & s.d $d_{\mathrm{ecl}}$ & $\tau$ & $\psi_{\mathrm{EL}}$ & Amp \\
\hline Scandinavia & $\begin{array}{l}15.6 \pm 1.7 \\
(n=7)\end{array}$ & $\begin{array}{l}2.1 \pm 0.6 \\
(n=6)\end{array}$ & $\begin{array}{l}24.9 \pm 0.7 \\
(n=7)\end{array}$ & $\begin{array}{l}11.9 \pm 1.0 \\
(n=7)\end{array}$ & $\begin{array}{l}12.4 \pm 1.3 \\
(n=6)\end{array}$ \\
\hline Canary Islands & $\begin{array}{l}18.4 \pm 1.3 \\
(n=5)\end{array}$ & $\begin{array}{l}1.4 \pm 0.3 \\
(n=5)\end{array}$ & $\begin{array}{l}25.8 \pm 0.5 \\
(n=5)\end{array}$ & $\begin{array}{l}11.0 \pm 1.6 \\
(n=5)\end{array}$ & $\begin{array}{l}14.2 \pm 0.9 \\
(n=5)\end{array}$ \\
\hline$P$ & $0.01^{*}$ & $0.02 *$ & $0.03^{*}$ & $0.3^{\mathrm{NS}}$ & $0.03^{*}$ \\
\hline
\end{tabular}




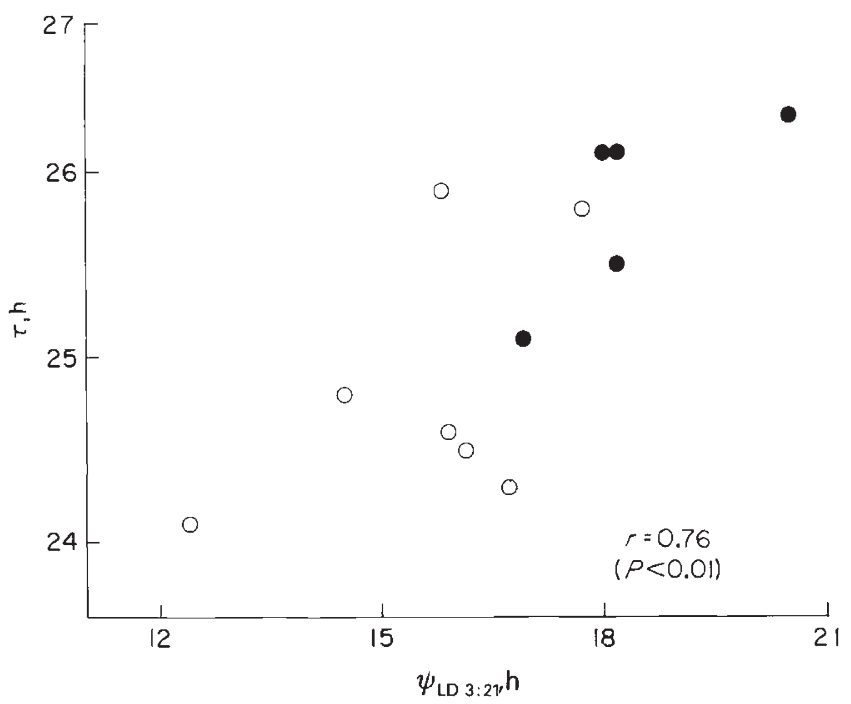

Fig. 5 Relation between period of free-running rhythm $(\tau)$ and phase of eclosion in light-dark cycle LD 3:21 ( $\left.\psi_{\mathrm{LD} 3: 21}\right)$ in strains of $D$. subobscura from Scandinavia (open circles) and the Canary Islands (filled circles).

In spite of abundant variability within Scandinavia or the Canary Islands (Table 1), the means of the two regions differed from each other in most rhythm parameters (Table 2). In the north the phase of entrained rhythm was earlier, the period of free-running rhythm shorter, and the amplitude of the rhythm lower.

Some other species of Drosophila have been studied for geographical variability in their eclosion rhythms. All of them have been photoperiodic species, and the studies have focused on relating geographically variable photoperiodism to the circadian rhythmicity of the species. In European populations of D. littoralis originating between $42-69^{\circ} \mathrm{N}$, the range of $\psi_{\mathrm{LD} 3: 21}$ was $8.9 \mathrm{~h}$ (57 strains), and of $\tau, 5.5 \mathrm{~h}$ ( 27 strains) (Lankinen, 1986a). In four Japanese $\left(34-43^{\circ} \mathrm{N}\right)$ strains of $D$. auraria, an Asiatic member of the $D$. melanogaster species group, the phase of the entrained rhythm varied about $2 \mathrm{~h}$, and $\tau$ about $0.5 \mathrm{~h}$ (Pittendrigh \& Takamura, 1989). By artificial selection the range was increased to $6 \mathrm{~h}$ and $2.5 \mathrm{~h}$, respectively (Pittendrigh \& Takamura, 1987). This shows that there is even more variability in natural populations than was directly observed in these four strains. In 12 European $\left(41-65^{\circ} \mathrm{N}\right)$ strains of $D$. phalerata, $\psi_{\mathrm{LD} 3: 21}$ varied by $3.1 \mathrm{~h}$, and $\tau$ by 1.3 (Lankinen, 1987). Lankinen (1985) lists the range of $\psi_{\mathrm{LD} 3: 21}$ in the following species: in $D$. transversa (12 Finnish and Central European strains) $4.6 \mathrm{~h}$, in $D$. montana (16 Finnish and North American strains) $5.5 \mathrm{~h}$, in D. ezoana (8 Finnish and Japanese strains) $4.7 \mathrm{~h}$, in $D$. lummei (16 Finnish strains) $6.0 \mathrm{~h}$, and in the non-photoperiodic species $D$. virilis $(7$
European and North American strains) $2.2 \mathrm{~h}$. The only negative result of geographical variability in drosophilids is in Chymomyza costata, where seven strains from Finland and Japan had weak but almost similar rhythmicity (Lankinen \& Riihimaa, 1992).

Genetic variability in laboratory strains can be explored by artificial selection on eclosion time. In the non-photoperiodic species $D$. pseudoobscura the change in the phase of eclosion time was about $4 \mathrm{~h}$ (Pittendrigh, 1967). In D. melanogaster, the response to selection on eclosion time was also clear (Clayton \& Paietta, 1972).

The existence of a sizeable amount of geographical variation in circadian eclosion rhythm in species of Drosophila seems to be the rule rather than the exception.

\section{The adaptive significance of latitudinal variation in eclosion rhythms}

Eclosion should be in phase with environmental light and temperature cycles. The strain differences of $D$. subobscura are expressed also in diel temperature cycles both in continuous light and in continuous darkness (Lankinen, 1993b). In the wild, flies do not probably free-run, but the properties of the selfsustaining circadian oscillator are expressed, in a quite complicated way, in light-dark cycles through the period of the rhythm, and through the parameters of the phase response curve (Pittendrigh, 1966).

In a given light-dark cycle, northern strains of $D$. subobscura eclose earlier than southern strains. This is a clear indication of a latitudinal cline, even though intermediate strains were not studied. This kind of latitudinal variation results in eclosion in the early morning at all latitudes (Lankinen, 1986a). A north-south difference of the same sort as in $D$. subobscura, was seen in the phase of eclosion of most Drosophila species cited in the preceding section.

\section{Geographically variable quantitative characters in D. subobscura}

At least the following quantitative characters are geographically variable in European populations of $D$. subobscura. Wing length and body size increase towards the north (Prevosti, 1955; Pfriem, 1983). Developmental time and viability of egg-to-adult depend on locality (Budnik et al., 1991). Developmental times of pupa-to-adult were dependent on strain (this study), and correlated with $\tau$ in the same way as among the per mutants of $D$. melanogaster (Kyriacou et al., 1990). Ethological isolation and mating speed vary (Brncic \& Budnik, 1984), but any geographical 
patterns remain tentative. The number of recessive lethal and deleterious alleles is smaller in marginal than in central populations (Pfriem \& Sperlich, 1982; Saura et al., 1990). The present study adds to the list the latitudinal variation in circadian eclosion rhythm.

\section{The aberrant rhythm of Kristiansand}

The partial arrhythmicity in Kristiansand was caused by segregation of a gene giving an almost arrhythmic phenotype when homozygous (results in Lankinen, 1993b). Considering the small number of strains studied, the finding of such a mutant was fortunate, and is the first demonstration of a spontaneously generated arrhythmic mutant in drosophilids. Some novel phenotypic characteristics and the autosomal location of this mutant imply that it is a new locus affecting circadian rhythms in Drosophila (Lankinen, 1993b). In the blowfly Lucilia cuprina, arrhythmic mutants are frequent in natural populations (Smith, 1987), but in D. subobscura this naturally occurring arrhythmic mutant should be regarded as rare.

\section{Variability in the adult locomotor activity rhythm of D. subobscura?}

In D. melanogaster adult locomotor activity and eclosion rhythms are controlled by the same circadian clock, but not in D. pseudoobscura (Engelmann \& Mack, 1979). The relationship of the two rhythms in $D$. subobscura is not yet known, but will be seemingly straightforward to work out in the future, as variability in one of the rhythms is now known.

Cabrera et al. (1985) found diel differences in allozyme frequencies in natural populations of $D$. subobscura in the Canary Islands, and similarly Gosteli (1991) found diel differences in inversion frequencies in samples taken from Swiss natural populations. As the authors remark, their results are possible only if there were genetic polymorphism in circadian flight activity rhythm. Their results thus imply variability also in the adult activity rhythm of $D$. subobscura, but there is not yet direct proof for this.

\section{Relations between the rhythm characteristics}

From the statistical analysis of the rhythm characteristics, some of these were correlated (Table 3). However, without genetic experiments, the causal relation (common genetic basis) between the traits remains uncertain. In the strains, the early phase of the entrained rhythm was correlated with the short period of the free-running rhythm (Fig. 5). More than half the variability in one was explained by the other $\left(r^{2}=0.57\right)$.
Figure 5 shows how this relation is also conserved within the main localities as well $\left(r^{2}=0.27\right.$ in Scandinavia and 0.55 in the Canary Islands). Accordingly, there may be a partially common genetic basis.

The two parameters of the amplitude of the rhythm

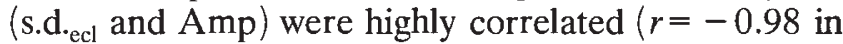
Table 3 ). The correlation is probably causal: the same genetic variable was expressed both in entraining light-dark conditions and in continuous darkness.

Circadian rhythmicity may be connected with photoperiodism. In photoperiodism, there is a seasonal day-length response that alters physiological status such as flowering or non-flowering, diapause or development. In earlier studies on drosophilids, geographical (latitudinal) variation in circadian rhythmicity has been searched for in species having differences in their photoperiodism (Lankinen, 1985, 1986b; Pittendrigh \& Takamura, 1987; Lankinen \& Riihimaa, 1992). Variability of circadian rhythms, too, has been found. In addition, genetic linkage between photoperiodism and overt circadian rhythms has been demonstrated (Lankinen, 1986b). A common genetic basis has, however, often remained unconfirmed, or variability of the two traits has been based on different loci (Lankinen, 1993a). My present study may be the first search for latitudinal variability in circadian eclosion rhythm of a non-photoperiodic drosophilid species. To conclude, circadian eclosion rhythm in a non-photoperiodic species can vary latitudinally in a fashion similar to most photoperiodic species.

\section{Acknowledgements}

I am grateful to Dr Jose Larruga for generously sending the strains from the Canary Islands, and Professor Seppo Lakovaara and Dr Anneli Hoikkala for collecting some of the Scandinavian strains. The analysis of results was greatly helped by computer programs made by Dr Jaakko Lumme. Phil. Lic. Ari Riihimaa helped in determining the photoperiodic diapause. Professor Anssi Saura (Umeå) made many helpful suggestions to the manuscript, and revised the English.

\section{References}

AFONSO, J. M., VOLTZ, A., HERNÁNDEZ, M., RUTTKAY, H., GONZÁLEZ, M., LARRUGA, J. M., CABRERA, V. M. AND SPERLICH, D. 1990. Mitochondrial DNA variation and genetic structure in Old-World populations of Drosophila subobscura. Mol. Biol. Evol., 7, 123-142.

BEGON, M. 1976. Temporal variations in the reproductive condition of Drosophila obscura Fallén and D. subobscura Collin. Oecologia, Berl., 23, 31-47.

BRNCIC, D. AND BUDNIC, N. 1984. Experiments on sexual isolation between Chilean and European strains of Drosophila subobscura. Experientia, 40, 1014-1016. 
BUDNIK, M., CIFUENTES, L. AND BRNCIC, D. 1991. Quantitative analysis of genetic differentiation among European and Chilean strains of Drosophila subobscura. Heredity, 67, 29-33.

CABRERA, v. M., GONZÁlEZ, A. M., HERnÁNDEZ, M., LARRUGA, J. M. AND MARTELL, M. 1985. Microgeographic and temporal genetic differentiation in natural populations of Drosophila subobscura. Genetics, 110, 247-256.

CLAYTON, D. L. AND PAIETTA, J. v. 1972. Selection for circadian eclosion time in Drosophila melanogaster. Science, 178, 994-995.

ENGELMANN, W. AND MACK, J. 1979. Different oscillators control the circadian rhythms of eclosion and activity in Drosophila. J. Compl. Physiol., 33, 583-608.

Gosteli, M. 1991. Differential flight activity among karyotypes: daily and weather-induced changes in chromosomal inversion polymorphism in natural populations of Drosophila subobscura. Genetica, 84, 129-136.

HALl, J. C. 1990. Genetics of circadian rhythms. Annu. Rev. Genet., 24, 659-697.

IKEDA, H. AND SAITO, M. 1983. Effects of circadian eclosion rhythm and temperature on estimating the relative rate of development in Drosophila mercarotum. Zoological Magazine, 92, 174-179.

KONOPKA, R. J. AND BENZER, s. 1971. Clock mutants of Drosophila melanogaster. Proc. Natl. Acad. Sci. U.S.A., 68, 2112-2116.

KRIMBAS, C. B. AND LOUKAS, M. 1980. The inversion polymorphism of Drosophila subobscura. Evol. Biol., 12, 163-234.

KRIMBAS, C. B. AND POWELL, J. R. 1992. Inversion Polymorphism of Drosophila. CRC Press, Boca Raton, Florida.

KYRIACOU, C. B., OLDROYD, M., WOOD, J., SHARP, M. AND HILL, M. 1990. Clock mutations alter developmental timing in Drosophila. Heredity, 64, 395-401.

LANKINEN, P. 1985. Genetic variation of circadian eclosion rhythm, and its relation to photoperiodism in Drosophila littoralis. Doctoral dissertation, University of Oulu.

LANKINEN, P. 1986a. Geographical variation in circadian eclosion rhythm and photoperiodic adult diapause in Drosophila littoralis. J. Comp. Physiol. A, 159, 123-142.

LANKINEN, P. 1986b. Genetic correlation between circadian eclosion rhythm and photoperiodic diapause in Drosophila littoralis. J. Biol. Rhythms, 1, 101-118.

LANKINEN, P. 1987. Latitudinal variation of time measurement in Drosophila phalerata. Proc. 10th Eur. Drosoph. Res. Conf., Barcelona, 157.

LANKINEN, P. 1993a. Independent inheritance of photoperiodic diapause and circadian eclosion rhythm in long term crosses between geographically variable strains of Drosophila littoralis. J. Biol. Rhythms, in press.

LANKINEN, P. $1993 \mathrm{~b}$. Characterization of linne, a new autosomal eclosion rhythm mutant in Drosophila subobscura. Behavior Genetics, 23, in press.

LANKINEN, P. AND LUMME, J. 1982. An improved apparatus for recording the eclosion rhythm in Drosophila. Dros. Inf. Serv., 58, 161, 163.

LANKINEN, P. AND RIIHIMAA, A. J. 1992. Weak circadian eclosion rhythmicity in Chymomyza costata (Diptera: Drosophilidae), and its independence of diapause type. J. Insect Physiol., 38, 803-811.
LATORRE, A., HERNÁNDEZ, C., MARTÍNEZ, D., CASTRO, J. A., RAMÓN, M. AND MOYA, A. 1992. Population structure and mitochondrial DNA gene flow in Old World populations of Drosophila subobscura. Heredity, 68, 15-24.

PFRIEM, P. 1983. Latitudinal variation in wing size in Drosophila subobscura and its dependence on polygenes of chromosome O. Genetica, 61, 221-232.

PFRIEM, P. AND SPERLICH, D. 1982. Wild chromosomes O of Drosophila subobscura from different geographic regions have different effects on viability. Genetica, 60, 49-59.

PITTENDRIGH, C. s. 1966. The circadian oscillation in Drosophila pseudoobscura pupae: a model for the photoperiodic clock. Z. Pflanzenphysiol. Bd., 54, 275-307.

PITTENDRIGH, C. s. 1967. Circadian systems, I. The driving oscillation and its assay in Drosophila pseudoobscura. Proc. Natl. Acad. Sci. U.S.A., 58, 1762-1767.

PITTENDRIGH, C. S. 1981. Circadian organization and the photoperiodic phenomena. In: Follet, B. K. and Follet, D. E. (eds) Biological Clocks in Seasonal Reproductive Cycles, Wright, Bristol, pp. 1-35.

PITTENDRIGH, C. S. AND TAKAMURA, T. 1987. Temperature dependence and evolutionary adjustment of critical night length in insect photoperiodism. Proc. Natl. Acad. Sci. U.S.A., 84, 7169-7173.

PITTENDRIGH, C. S. AND TAKAMURA, T. 1989. Latitudinal clines in the properties of a circadian pacemaker. J. Biol. Rhythms, 4, 217-235.

PREVOSTI, A. 1955. Geographical variability in quantitative traits in populations of Drosophila subobscura. Cold Spring Harb. Symp., 20, 294-299.

PREVOSTI, A. 1968. Efecto de la cordillera pirenaica sobre la distribución geographica de las ordenaciones cromosómicas de Drosophila subobscura. Pirineos, 79-80, 221-228.

PREVOSTl, A., RIBO, G., SERRA, L., AGUADE, M., BALAÑA, J., MONCLUS, M. AND MESTRES, F. 1988. Colonization of America by Drosophila subobscura: experiment in natural populations that supports the adaptive role of chromosomal-inversion polymorphism. Proc. Natl. Acad. Sci. U.S.A., 85, 5597-5600.

SAUNDERS, D. S., HENRICH, v. C. AND GILBERT, L. I. 1989. Induction of diapause in Drosophila melanogaster: photoperiodic regulation and the impact of arrhythmic clock mutations on time measurement. Proc. Natl. Acad. Sci. U.S.A., 86, 3748-3752.

SAURA, A., JOHANSSON, B., ERIKSSON, E. AND KOHONEN-CORISH, M. 1990. Genetic load in northern populations of Drosophila subobscura. Hereditas, 112, 283-287.

SAURA, A., LOKKI, J., LANKINEN, P. AND JÄRVINEN, O. 1973. Entsyymipolymorfismit populaatiogenetiikassa ja evoluutiotutkimuksessa. Luonnontutkija, 4-5, 101-111.

SMITH, P. H. 1987. Naturally occurring arrhythmicity in eclosion and activity in Lucilia cuprina. Physiol. Entomol., 12, 99-107.

WALTER, T. 1990. Über den Nachweis von Drosophila-Arten während des Winters im scweizerischen Mittelland. Mitteilungen der Schweizerischen Entomologischen Gesellschaft, 63, 115-120.

Winfree, A. T. 1980. The Geometry of Biological Time. Biomathematics, Vol. 8, Springer-Verlag, New York, 530 pp. 